\title{
Testicular Torsion in a 17 Year Old Boy: Role of School Health Education
}

\author{
Tijani Idris Ahmad Oseni*
}

Department of Family Medicine, Irrua Specialist Teaching Hospital, Irrua, Nigeria

${ }^{*}$ Corresponding author: Tijani Idris Ahmad Oseni, Department of Family Medicine, Irrua Specialist Teaching Hospital, Irrua, Nigeria, Tel: +2348036281897; E-mail: tijanioseni@yahoo.com

Received date: April 03, 2018; Accepted date: April 10, 2018; Published date: April 17, 2018.

Copyright: (C) 2018 Oseni TIA. This is an open-access article distributed under the terms of the Creative Commons Attribution License, which permits unrestricted use, distribution, and reproduction in any medium, provided the original author and source are credited.

Citation: Oseni TIA (2018) Testicular Torsion in a 17 Year Old Boy: Role of School Health Education.

\section{Abstract}

Introduction: Testicular torsion if not promptly recognised and managed could lead to testicular loss. It is common in young boys, therefore such loss would be associated with adverse consequences for the rest of the life of the patient. Health education to enlighten the public on the need for prompt presentation is vital in its management to increase rate of testicular salvage. This case report highlights the importance of prompt diagnosis and management of testicular torsion.

Observation: Presented was Mr AE a 17 year old student and only son of a widow who presented with thirty minutes history of right testicular pain. His mother wanted him to resort to self-medication but he insisted on going to the hospital based on advice of doctors during a school health programme a week earlier. He subsequently had right detorsion and orchidopexy and left orchidopexy on account of right testicular torsion.

Conclusion: Testicular torsion is a urological emergency and if promptly recognised and managed would save the patient from serious problems associated with testicular compromise. Health education of all age groups including students on the need for prompt presentation to health facility will increase the rate of testicular salvage.

Keywords: Testicular; Torsion; Detorsion; Orchidopexy

\section{Introduction}

Testicular torsion is a common urological problem [1]. 1 in 4,000 males below the age of 25 years are affected annually, globally [2-4]. It is a surgical emergency and common among young males presenting with scrotal pain particularly if it is of sudden onset [3-5].

This case of testicular torsion is presented to underscore the importance of knowledge of the condition by the public in the management of the condition as this will make patients present early because delay either in presentation, diagnosis or management can lead to testicular loss with its attendant consequences.

\section{Case Report}

He was $M r A E$, a 17 year old secondary school student who resided in Benin, Edo State, Nigeria. He was Esan and a Christian.

He presented to the accidents and emergency unit of the hospital with complaints of pain in the right hemi-scrotum of thirty minutes duration. He was awakened at the middle of the night by a sudden pain in his right hemi-scrotum thirty minutes prior to presentation. Pain was aching in nature, severe, nonradiating. There was no history of trauma and there was no associated frequency, dysuria, haematuria or urethral discharge. There was associated waist pain, but there was no fever, nausea or vomiting. Patient then decided to present to the teaching hospital. The mother wanted him to take some medications which she said would relieve the pain but patient insisted on going to the hospital. His insistence was because, a week prior to presentation, a team of doctors came to their school to give health talk on the need for prompt presentation to the hospital whenever there was a health challenge rather than resort to self-medications. There was no history of similar pain in the past. There was no history of urinary or genital tract infection in the past. Patient was not sexually active. He feared impotence/sterility from his condition which he believed was caused by infection. It has made him uncomfortable and he needed a cure. He has had no previous surgery. He was not a known hypertensive or diabetic and not a known sickle cell disease patient.

He was the second of seven children and the only son in a monogamous setting. He was in senior secondary 3 in the public school nearby. His father was a fifty seven year old mechanic who died of a road traffic accident three years earlier. Mother was a petty trader who sold food items in the local market. His older sibling was a mechanic and his younger ones where in school. They were being sponsored by the mother and the elder brother. He neither smoked cigarette nor drank alcohol. 
Examination findings revealed an adolescent, in acute painful distress, afebrile, not pale, anicteric, not dehydrated, no pedal oedema. He was $1.62 \mathrm{~m}$ tall and weighed $62 \mathrm{~kg}$ with a body mass index of $23.6 \mathrm{~kg} / \mathrm{m} 2$ which was normal. The left testis was normal. However the right testis was horizontal and tender. Prehn's sign was negative-with the patient standing the right testis was lifted upward, this did not relieve the pain. Cremasteric reflex was absent - on lightly stroking the superior and medial aspect of the right thigh, there was no upward pull of the testis from absence of cremasteric contraction. Pulse Rate was $78 \mathrm{bpm}$ regular, with normal volume, blood pressure was $110 / 70 \mathrm{mmHg}$ and first and second heart sounds only were heard. Respiratory rate was $20 \mathrm{cpm}$ and breath sounds were vesicular. Abdomen was full, soft, moved with respiration with no area of tenderness, no masses or organomegaly.

Rectal examination revealed normal findings.

An assessment of right testicular torsion was made with right epididymo-orchitis as differential. Patient and his mother were counseled on the diagnosis and the need for urgent scrotal exploration to salvage the testis. They were also counseled on the possibility of orchidopexy if the testis was not viable. Informed consent was obtained. Anaesthetist was called to review and Packed Cell Volume was done and was $43 \%$, Urine analysis was normal with a $\mathrm{pH}$ of 7 . Electrolytes, Urea and Creatinine were normal.

Scrotal exploration with right detorsion and orchidopexy and left orchidopexy was done under spinal anaesthesia with 2 $\mathrm{ml}$ of Bupivacaine after preloading with 1 litre of normal saline. Intra operative findings included:

- Healthy left testis

- Horizontal lying right testis rotated anticlockwise at an angle of 180.

With patient lying supine and under spinal anaesthesia as above, skin was cleaned with antiseptic agent (Savlon and povidone iodine) and draped. $4 \mathrm{~cm}$ transverse right scrotal crease incision was made and deepened through the dartos muscle and spermatic fascia to the tunica vaginalis which was incised and the right testis mobilised with the above findings noted. The testis was untwisted and fixed to the dartos muscle using interrupted vicryl 2/0 stitches. Dartos muscle was closed with vicryl 2 and vicryl 2/0 for skin closure. A similar incision was made on the left scrotum and the left testis was also mobilised and fixed to the dartos muscle using interrupted vicryl 2/0 stitches. Dartos muscle was closed with vicryl 2 and vicryl $2 / 0$ for skin closure. Immediate post-operative condition was satisfactory and estimated blood loss was $40 \mathrm{ml}$. He was placed on intravenous ciprofloxacin $200 \mathrm{mg} 12$ hourly, metronidazole 500 mg 8 hourly, intramuscular pentazocine 30 mg 6hourly all for $24 \mathrm{hrs}$.

On the first day post operation, patient was recovering well, vital signs were satisfactory. He had no complaints. He was discharged and placed on Tabs Ciprofloxacin $500 \mathrm{mg}$ bd, Metronidazole $400 \mathrm{mg}$ tds, Vitamin C $200 \mathrm{mg}$ tds all for ten days and Diclofenac $50 \mathrm{mg}$ bd for five days after being counseled on the need present to the hospital anytime he had complaint. He was given a week appointment.
Patient was seen twice after surgery at one week and five weeks respectively and visits were uneventful. On the first follow up visit, he was counseled on the need to wear loose cotton panties for proper ventilation of the genitalia and to avoid nylon pants as well as tight fitting pants. He was then given a four weeks follow up appointment. Seminal fluid analysis done on second follow up visit (five weeks post operation) was normal with a count of $80 \times 106 / \mathrm{ml}$ and a motility and morphology of $70 \%$ and $75 \%$ respectively. Patient was then discharged from clinic.

\section{Discussion}

Testicular torsion is a common urological problem [1]. 1 in 4,000 males below the age of 25 years are affected annually, globally [2-4]. It is a surgical emergency and common among young males presenting with scrotal pain particularly if it is of sudden onset [3-5] as was the case with AE who was 17 years old and had sudden onset right testicular pain. Testicular torsion occurs when the testis is rotated causing twisting of the spermatic cord resulting in ischaemia and eventual necrosis $[2,5,6]$. Testicular torsion contributes to male infertility $[4,7]$ accounting for $5.8 \%$ of causes of testicular insufficiency according to a study by Bello et al in Zaria, Northeastern Nigeria [7].

The cause of testicular torsion is unknown but certain anatomical conditions like clapper bell deformity (failure of normal posterior anchoring of gubernaculum, epididymis and testis), horizontal lie and mal-descended testis increases the likelihood of occurrence $[1,2,8,9]$. It may follow trauma and commonly occur when patient is asleep as was seen in AE [4]. Testicular torsion would more likely cause testicular death within six hours if not reversed [2,4,5]. Early recognition and prompt surgical management [10] is therefore necessary to prevent necrosis of the affected testis as when this occur the non-viable testis has to be removed. The testicular salvage rate is $50 \%$ globally and much less in developing countries (about $32 \%$ in Nigeria) [4]. Testicular pain in adolescents and young adults should be considered to be testicular torsion until proven otherwise [2]. This high index of suspicion will facilitate prompt management and thus increase testicular salvage.

Testicular loss usually occurs when there is delay in surgery [2]. This is usually due to a delay in seeking medical attention[2], incorrect initial diagnosis [2], delay in referral from the health personnel patient first have contact with $[5,8]$ and delay in surgery at the referral hospital [2]. $\mathrm{Mr} A E$ presented within two hours of symptoms and had urgent scrotal exploration. His prompt presentation was due to the lectures received by a team of health experts who came to their school on school health programme. This underscores the importance of school health programmes and other forms of public enlightenment and health education.

As Family Physicians, who are usually the first level of contact in most settings, we should have a high index of suspicion and proper training to be able to diagnose and effectively manage testicular torsion surgically to prevent testicular loss [2]. Scrotal exploration is advocated once there 
is possibility of torsion $[1,8]$. This is particularly so in resource poor settings where facilities are lacking for Doppler ultrasound studies which enhances diagnosis [11] and movement to centres where facilities exist would cause undue delay and increased chance of testicular loss with variable reproductive compromise [2].

Also, as health educators, family physicians should engage in activities that will educate the public on issues of health concern whenever the opportunity present itself as well as organise school health programmes as well as advocacy for healthy living.

\section{References}

1. Irekpita E, Kesieme E, Kalu Q, Onuora V (2011) Testicular torsion: An analysis of sixteen consecutive cases and a review of the literature. J Clin Diagn Res 5: 1413-1415.

2. Ringdahl $E$, Teague $L(2006)$ Testicular torsion. Am Fam Physician J 75: 1739-1743.

3. Karen C, Ja Neille S, Gerry H (2011) Testicular torsion: A case study and evaluation of young men's knowledge about testicular pain. W Va Med J 107: 35-37.
4. Solademi OB, Oshiname FO, Sotunsa JO (2014) Awareness and Sources of Information Relating to Testicular Self-Examination and Torsion among Male Undergraduates in a Nigerian University. Int J Med Med Sci 1: 143-150.

5. Baruga E, Munabi IG (2013) Case series on testicular torsion: an educational emergency for sub-Saharan Africa. Pan Afr Med J 14:18.

6. Njeze GE (2012) Testicular torsion: Needless testicular loss can be prevented. Nigerian J Clin Practice 15: 182-184.

7. Ahmed A, Bello A, Mbibu NH, Maitama HY, Kalayi GD (2010) Epidemiological and aetiological factors of male infertility in northern Nigeria. Nigerian J Clin Practice 13: 205-209.

8. Ibrahim AG, Aliyu S, Mohammed BS, Ibrahim H (2012) Testicular torsion as seen in University of Maiduguri teaching Hospital, North Eastern Nigeria. Borno Med J 9: 31-33.

9. Njeze GI, Nzegwu MA (2012) Surgical emergencies as seen in a private hospital in Enugu, Nigeria. Adv Bioresearch 3: 101-104.

10. Eke N, Sapira MK, Echem RC (2007) Spectrum of urological procedures in University of Port Harcourt Teaching Hospital, Port Harcourt, Nigeria. Nigerian J Clin Practice 10: 74-78.

11. Ndaguatha PLW (2009) Misdiagnosed adult testicular torsion: Case report. East Afr Med J 86: 41-44. 